\title{
Indications of sentinel node biopsy in thin melanoma
}

\author{
Indicações de biópsia do linfonodo sentinela em melanomas finos
}

\author{
Fernanda Braga Silva ${ }^{1}$, Renato Santos de Oliveira Filho ${ }^{2}$, Wagner Iared ${ }^{3}$, Álvaro Nagib Atallah ${ }^{4}$, \\ Ivan Dunchee de Abranches Oliveira Santos ${ }^{5}$, Lydia Masako Ferreira ${ }^{6}$
}

\begin{abstract}
Objective: To assess data on survival, recurrence and histological factors in positive and negative sentinel lymph nodes in thin melanoma cases. Methods: A systematic review was conducted on observational studies in four databases (Cochrane Library, Medline, Embase and Lilacs). Positive and negative micrometastases in sentinel lymph node biopsy were compared regarding the clinical outcomes - death and recurrence - and six histological factors vertical growth phase, Breslow thickness, Clark level, ulceration, regression and mitosis rate. Results: Positive sentinel lymph node is statistically associated with greater risk of death in six studies (OR: 7.2; $95 \% \mathrm{Cl}[2.37-21.83] ; I^{2} 0 \%$ ) and also to recurrence in three studies (OR: 30.7; 95\%Cl [12.58-74.92]; / $236 \%$ ). Comparing positive and negative groups, the histological factors predicting positive sentinel nodes and poor prognosis were: mitosis rate $\geq 5 / \mathrm{mm}^{2}$ (OR: 16.29; 95\% CI [3.64-72.84]; $l^{2} 40 \%$ ); VGP (OR: $2.93 ; 95 \% \mathrm{Cl}$ [1.08-7.93]; $/^{2}$ 59\%); Breslow thickness $\geq 0.75 \mathrm{~mm}$ (OR: 2.23; 95\%Cl [1.29-3.86]; $I^{2} 0 \%$ ); and Clark level IV-V (OR: $1.61 ; 95 \% \mathrm{Cl}[1.06-2.44]$; ${ }^{2} 34 \%$ ). Conclusions: The statistically significant results associated with the presence of micrometastases in thin melanomas were Breslow thickness $\geq 0.75 \mathrm{~mm}$, Clark level IV-V and mitoses $\geq 5 / \mathrm{mm}^{2}$, absence of regression. This histological factor of ulceration was associated, but not statistically significant.
\end{abstract}

Keywords: Sentinel lymph node biopsy; Melanoma; Lymph nodes

\section{RESUMO}

Objetivo: Avaliar dados sobre sobrevida, recorrência e fatores histológicos nos casos de linfonodo sentinela positivo e negativo em melanomas finos. Métodos: Realizou-se uma revisão sistemática de estudos observacionais em quatro bancos de dados (Biblioteca Cochrane, Medline, Embase e Lilacs). Micrometástases positivas e negativas em biópsia de linfonodo sentinela foram comparadas com relação aos desfechos clínicos - morte e recorrência - e a seis fatores histológicos dos melanomas finos - fator de crescimento vertical, índice de Breslow, nível de Clark, ulceração, regressão e índice mitótico. Resultados: Linfonodo sentinela positivo está estatisticamente associado a maior risco de morte em seis estudos (OR: 7,2; IC95\% [2,37-21,83]; / $2 \%$ ) e associa-se a maior recorrência em três estudos (OR: 30,7; IC95\% [12,58-74,92]; $I^{2} 36 \%$ ). Os fatores histológicos preditivos de positividade do linfonodo sentinela com associação estatisticamente significativa são: índice mitótico $\geq 5 / \mathrm{mm}^{2}$ (OR: 16,29 ; IC95\% [3,64-72,84]; I $^{2} 40 \%$ ); fase de crescimento vertical (VGP) (OR: 2,93; IC95\% [1,08-7.93]; /2 59\%); Breslow $\geq 0,75 \mathrm{~mm}$ (OR: 2,23; IC95\% [1,29-3,86]; /2 0\%); e nível de Clark IV-V (OR: 1,61; IC95\% $[1,06-2,44] ; / 234 \%)$. Conclusões: 0 s seguintes resultados estavam associados à presença de micrometástases nos melanomas finos $\mathrm{e}$ foram estatisticamente significativos: Breslow $\geq 0,75 \mathrm{~mm}$, Clark IV-V, índice mitótico $\geq 5 / \mathrm{mm}^{2}$ e ausência de regressão. 0 fator histológico ulceração foi associado à presença de micrometástases, porém, sem significância estatística.

Descritores: Biópsia de linfonodo sentinela; Melanoma; Linfonodos

\section{INTRODUCTION}

The presence of positive sentinel nodes had a statistically significant association with higher numbers of deaths and recurrences. The histological factors that were significantly associated with the presence of lymph node micrometastasis were as follows: Breslow thickness $\geq$ $0.75 \mathrm{~mm}$, Clark level IV-V, mitoses $\geq 5 / \mathrm{mm}^{2}$ and absence of regression.

Although ulceration did not show any statistically significant association with the presence of positive sentinel nodes, the analysis indicated a tendency towards it.

\footnotetext{
Study carried out at Department of Plastic Surgery of Universidade Federal de São Paulo - UNIFESP, São Paulo (SP), Brazil.

' Resident in Dermatology at Universidade Federal de São Paulo - UNIFESP, São Paulo (SP), Brazil.

${ }^{2}$ PhD; Volunteer faculty at the Department of Plastic Surgery of Universidade Federal de São Paulo - UNIFESP, São Paulo (SP), Brazil.

${ }^{3} \mathrm{MD}$; Postgraduate student at Centro Cochrane do Brasil , São Paulo (SP), Brazil.

${ }^{4}$ Post-doctorate degree; Coordinator at the Centro Cochrane do Brasil, São Paulo (SP), Brazil.

${ }^{5}$ PhD; Head at the Department of Plastic Surgery of Universidade Federal de São Paulo - UNIFESP, São Paulo (SP), Brazil.

${ }^{6} \mathrm{PhD}$; Head of the Department of Surgery of Universidade Federal de São Paulo - UNIFESP, São Paulo (SP), Brazil.

Corresponding author: Fernanda Braga Silva - Rua Loefgreen, 1682, apto. 11 - Vila Clementino - CEP 04040-032 - São Paulo (SP), Brazil - Tel.: (12) 3922-3315 - e-mail: febragas@hotmail.com

Received on Jul 25, 2009 - Accepted on Apr 12, 2010

Conflicts of interest: None. This article is a systematic review and it is looking for the best management in practice.
} 
Sentinel node biopsy (SNB) is used to predict recurrence of cutaneous melanoma and to assess patient's survival. This technique is very important because it optimally stages early melanoma and allows greater accuracy for individualized prognosis. In addition, when sentinel node biopsy is combined with immediate lymphadenectomy for sentinel node metastases, it can improve overall disease-free survival (an accepted endpoint in cancer trials).

The overall incidence of melanoma has been rising all over the world and the proportion of thin melanoma (Breslow thickness $\leq 1 \mathrm{~mm}$ ) has increased in relation to occurrences of more deeply infiltrating lesions. Sentinel node biopsy has proved to be an accurate procedure for staging regional node status with minimal morbidity. Sentinel node status is the most important prognostic factor for localized melanoma ${ }^{(1,2)}$. The sentinel node biopsy procedure was developed to identify the $20 \%$ of patients with intermediate thickness primary melanomas (1-4 mm) who had regional lymph node metastasis $^{(1)}$. There is great interest in learning more about sentinel lymph node biopsy within the subgroup of thin melanomas.

Thin melanomas are considered highly curable by means of wide local excision alone, with reported fiveyear disease-free survival rates of $95-98 \%{ }^{(3)}$. In view of the low incidence of regional lymph node metastases, indications for lymphatic mapping and sentinel node biopsy in such patients appear to be questionable. Other factors that limit indications for this technique are its cost and the very small but real chance of complications.

Although sentinel node biopsy is widely accepted for intermediate melanoma, its use for thin melanomas remains controversial ${ }^{(4)}$. In some cases, with Breslow thickness $\leq 1 \mathrm{~mm}$, the procedure can be carried out in the presence of histopathologically poor prognostic features, such as ulceration and regression ${ }^{(5-6)}$. Indeed, ulceration and regression have been associated with metastatic potential in thin melanoma cases and are recognized by some authors as a predictive factor for positive sentinel lymph nodes ${ }^{(5-6)}$.

\section{OBJECTIVE}

To evaluate the association between positive sentinel lymph node and poor prognosis in thin melanoma patients and the correlation between histological factors and a positive sentinel node biopsy.

Hypothesis: sentinel lymph node biopsy can be indicated for selected patients with thin melanoma (presence of histological factors that may be associated with micrometastases), in order to predict prognosis.

\section{METHODS}

\section{CRITERIA FOR CONSIDERING STUDIES TO BE REVIEWED}

- Types of studies

Studies assessing death and recurrence in thin melanoma patients undergoing sentinel node biopsy. Studies were included irrespective of publication status, language or blinding.

- Types of participants

Thin melanoma patients who underwent sentinel node biopsy.

- Types of intervention

None.

- Types of outcome measurement

Death;

Disease recurrence.

- Histological factors in thin melanomas:

- Vertical growth phase;

- Breslow;

- Clark level;

- Ulceration;

- Regression;

- Mitoses.

\section{STRATEGY FOR IDENTIFYING STUDIES}

Studies were identified by searching the Cochrane Library, Medline, Embase and Lilacs databases (2000-2008).

The following search strategy was constructed by using a combination of subject headings and text words relating to sentinel lymph node biopsy in melanomas.

\section{Medline search strategy}

The following search terms were combined to find studies for inclusion in the review: melanomas, sentinel node, sentinel node biopsy.

In addition, experts in this subject were contacted to investigate data that had not been published.

\section{REVIEW METHODS}

- Application of inclusion criteria

Two reviewers applied the inclusion criteria to all potential studies. The reviewers were not blinded to the report authors' names, journals, dates of publication, sources of financial support or results.

The inclusion criteria were:

A. Sentinel lymph node biopsy in thin melanomas;

B. Comparison between positive and negative sentinel lymph nodes.

\section{- Data extracted}


The following pre-specified characteristics of all studies were independently extracted by the two reviewers. In cases of discrepancy, the opinion of a third reviewer was sought in order to reach a consensus.

Method: diagnostic procedures, melanoma thickness, positive and negative sentinel lymph nodes, histological factors and follow-up.

Participants: some articles reported data on sex and age.

Intervention: none.

Outcomes: recurrence and death rates in the groups with positive or negative sentinel lymph nodes.

\section{STATISTICAL METHODS}

All analyses were performed using the RevMan 5.0.18 software package for dichotomous variables. Odds Ratios and confidence intervals were calculated.

The heterogeneity analyzed by means of $I^{2}$ statistics (differences in reported effect), methodological heterogeneity (differences in study design) and clinical heterogeneity (differences between studies regarding participants' characteristics or outcome measurements) were explored. Statistical heterogeneity was assessed both by inspection of graphical presentations and by calculation of confidence intervals. When heterogeneity was found, the potential causes of this heterogeneity were explored.

\section{RESULTS}

Our search yielded 32 potentially relevant articles out of 1,734 abstracts examined. These published papers described 32 original studies: 30 case series, one cohort and one case-control study. The articles were considered to describe a single study if they used the same study population. One case-control study was excluded because the research focus was on estimating the cost of a positive sentinel lymph node. Another 11 case series were excluded because they did not compare positive and negative sentinel lymph node results or did not set out the results in a way that allowed meta-analysis. Altogether, 20 studies were included in nine meta-analyses (Figure 1). These studies had been published between 2000 and 2008. In total, 4,493 sentinel lymph nodes were excised and 221 of them were positive $(4.9 \%)$, with micrometastases. The population size in the studies ranged from 21 to 465 patients, and the number of positive sentinel lymph nodes ranged from 1 to 34 . The gender and age distribution was not specified in all studies. Most of the studies evaluated the vertical growth phase, Breslow thickness, Clark level, ulceration, regression, mitosis rate, recurrence and death. The duration of the followup ranged from 2 to 11 years (median of 6 years). Most of the studies had been conducted by analyzing medical data in melanoma referral centers. The SNB technique used was the same in all centers and the differences between the histopathological analyses were focused on immunohistochemistry. The immunohistochemical stains most often consisted of S-100, Melan-A and HMB-45.

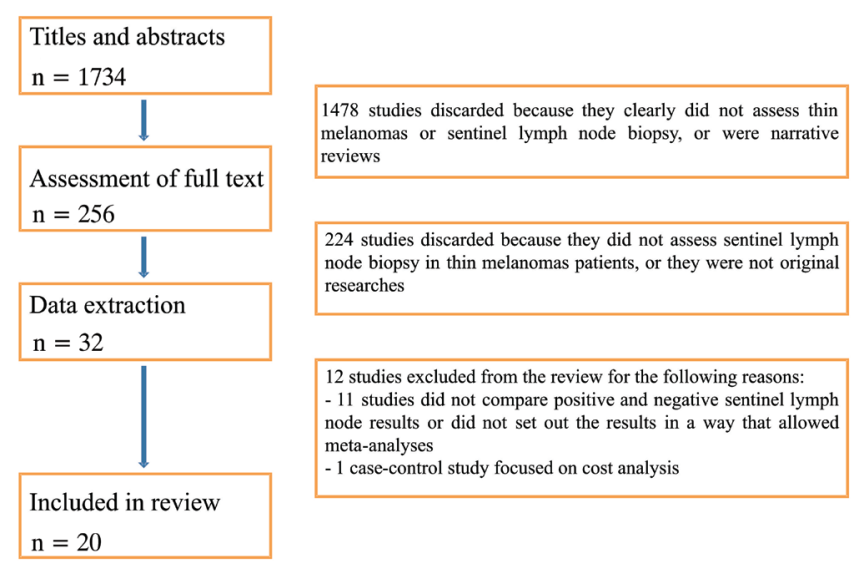

Figure 1. Inclusion process

Death and recurrence values were assessed (Figures 2 and 3). Positive sentinel lymph nodes were associated with greater numbers of deaths; six studies ${ }^{7-}$ 12) analyzed this association. The positive sentinel lymph node group had a total of 52 cases with 2 deaths; the negative sentinel lymph node group had 1,219 cases with 19 deaths (OR: 7.2; 95\% CI [2.37-21.83]; $I^{2} 0 \%$ ). Positive sentinel lymph nodes were associated with recurrence in three studies ${ }^{(7,10,12)}$. These three studies analyzed this association in 26 positive sentinel nodes with 13 recurrences and in 698 cases of negative sentinel lymph nodes with 24 recurrences (OR: 30.7; 95\% CI [12.5874.92]; I236\%).

The other seven meta-analyses evaluated the correlations of histological factors with positive sentinel lymph nodes. The results were as follows:

Presence of the vertical growth phase was associated with micrometastases in thin melanomas. The metaanalysis included three studies ${ }^{(2,9,13)}$ with a total of 169 cases presenting a vertical growth phase and, of these, 16 had a positive sentinel lymph node. In the group without a vertical growth phase, there were 138 cases and five of these had a positive sentinel lymph node (OR: 2.93; 95\% CI [1.08-7.93]; I $I^{2} 59 \%$ ).

The Breslow thickness was subdivided into two groups: $\geq 0.75 \mathrm{~mm}$ and $<0.75 \mathrm{~mm}$. The meta-analysis included four studies ${ }^{(8,9,12,14)}$ with a total of 435 cases 


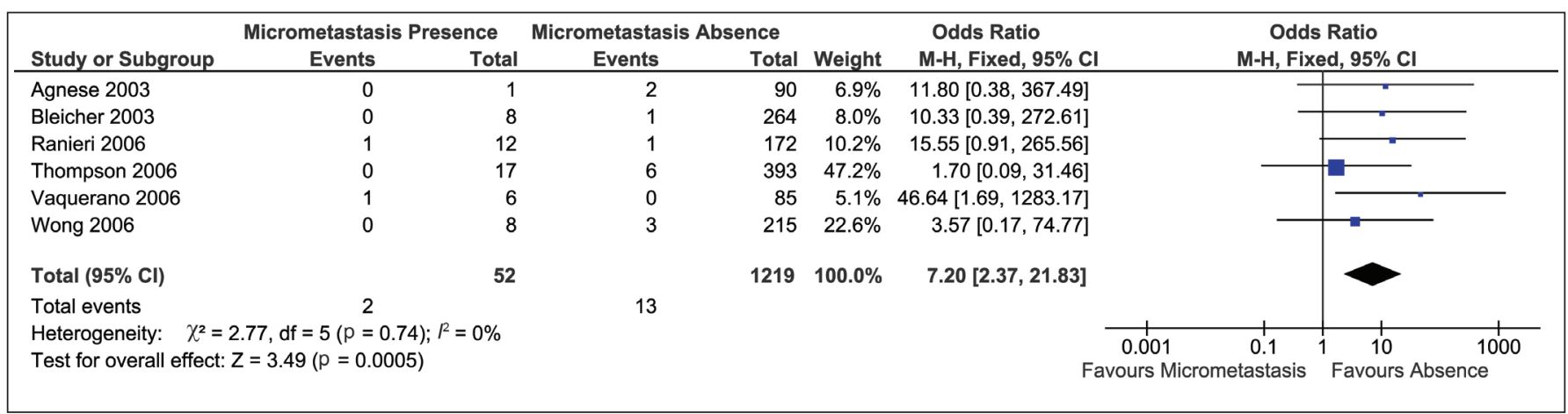

Figure 2. Deaths among groups with and without micrometastases

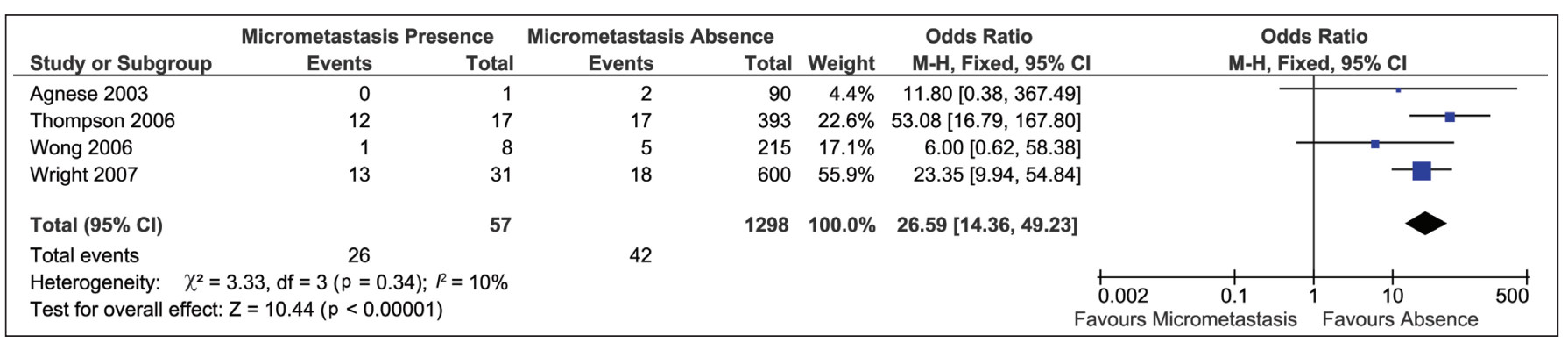

Figure 3. Recurrences among groups with and without micrometastases

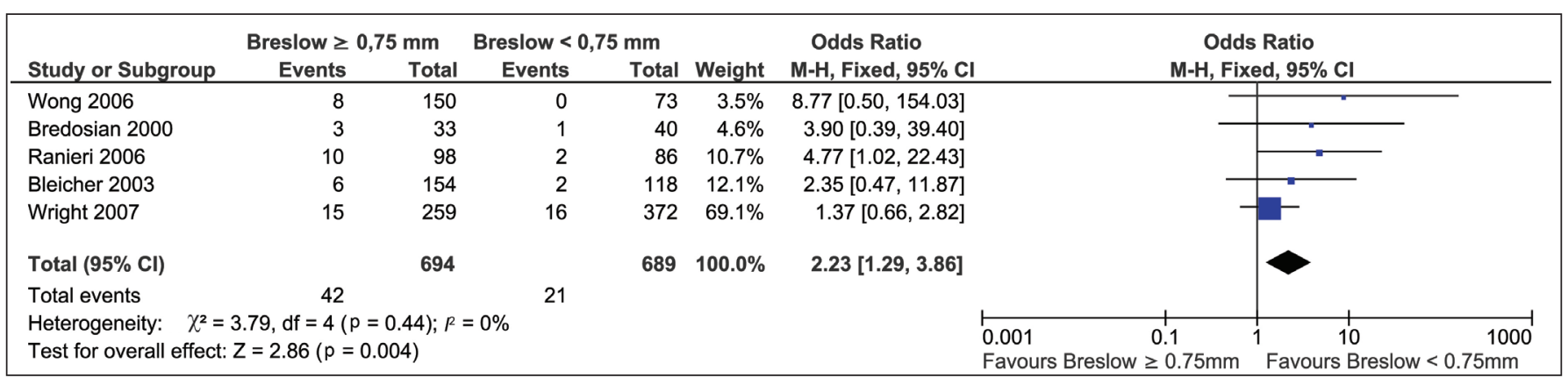

Figure 4. Presence of micrometastases in groups with Breslow thickness $\geq 0.75 \mathrm{~mm}$ and $<0.75 \mathrm{~mm}$

presenting Breslow $\geq 0.75 \mathrm{~mm}$, with 27 positive sentinel lymph nodes. In the group with Breslow $<0.75 \mathrm{~mm}$, there were 317 cases and five had a positive sentinel lymph node (Figure 4). There was an association between Breslow thickness $\geq 0.75 \mathrm{~mm}$ and presence of a positive sentinel lymph node (OR: 4.15; 95\% CI [1.62$10.64] ; I^{2} 0 \%$ ).

Clark levels IV and V were associated with the presence of micrometastases in thin melanomas (Figure 5). The meta-analysis included $10 \operatorname{articles}^{(2,4,9,11-13,15-18)}$ with a total of 803 cases in the group with Clark level IV-V and, out of these, 47 had a positive sentinel lymph node biopsy. In the group with Clark level I-III, there were 862 cases and 29 positive biopsies (OR: 2.18; 95\% CI [1.33-3.54]; $I^{2} 0 \%$ ).

Ulceration was associated with the presence of positive sentinel lymph nodes. Eight studies were included in the meta-analysis ${ }^{(2,4,9,12,13,17-19)}$. Ulceration was present in 67 cases and, out of these, 4 had a positive sentinel lymph node; 879 cases did not have ulceration and there were 44 positive sentinel nodes in the latter group (OR: 2.09 ; 95\% CI [0.86-5.07]; $I^{2} 0 \%$ ).

Regression was evaluated in eight studies ${ }^{(2,9,12,13,17,19-}$ 21) and was associated with negative sentinel lymph nodes. In total, 305 cases presented regression and, out of these, 6 had a positive sentinel lymph node. The other 569 did not present regression and had 38 positive sentinel nodes (OR: $0.44 ; 95 \%$ CI [0.2-0.97]; $I^{2} 40 \%$ ).

Mitosis rate $\geq 5 / \mathrm{mm}^{2}$ was associated with positive sentinel lymph nodes (Figure 6). Two studies were included in this meta-analysis ${ }^{(2,9)}$. In total, 29 cases presented mitosis rate $\geq 5 / \mathrm{mm}^{2}$ and, of these, 8 had a positive sentinel node. There were 232 cases with mitosis rate $<5 / \mathrm{mm}^{2}$ and 10 of these had a positive sentinel lymph node (OR: 16.29; 95\%CI [3.64-72.84]; I 40\%). 


\begin{tabular}{|c|c|c|c|c|c|c|c|c|c|}
\hline \multirow[b]{2}{*}{ Study or Subgroup } & \multicolumn{2}{|c|}{ Clark IV - V } & \multicolumn{2}{|c|}{ Clark I - III } & \multirow[b]{2}{*}{ Weight } & \multirow{2}{*}{$\begin{array}{l}\text { Odds Ratio } \\
\text { M-H, Fixed, } 95 \% \mathrm{Cl}\end{array}$} & \multirow{2}{*}{\multicolumn{3}{|c|}{$\begin{array}{c}\text { Odds Ratio } \\
\text { M-H, Fixed, } 95 \% \mathrm{Cl}\end{array}$}} \\
\hline & Events & Total & Events & Total & & & & & \\
\hline Cecchi 2007 & 1 & 2 & 1 & 48 & $0.1 \%$ & $47.00[1.56,1417.89]$ & & & \\
\hline Jacobs 2003 & 1 & 22 & 1 & 41 & $1.8 \%$ & $1.90[0.11,32.01]$ & & & \\
\hline Kesmodel 2005 & 6 & 77 & 3 & 104 & $6.5 \%$ & $2.85[0.69,11.76]$ & & & \\
\hline Lowe 2003 & 1 & 15 & 2 & 31 & $3.4 \%$ & $1.04[0.09,12.41]$ & & & \\
\hline Oliveira Filho 2003 & 4 & 40 & 2 & 37 & $5.2 \%$ & $1.94[0.33,11.30]$ & & & \\
\hline Puelo 2005 & 9 & 157 & 11 & 252 & $22.0 \%$ & $1.33[0.54,3.29]$ & & & \\
\hline Ranieri 2006 & 8 & 65 & 4 & 114 & $7.1 \%$ & $3.86[1.11,13.37]$ & & & \\
\hline Roulin 2007 & 3 & 23 & 1 & 28 & $2.2 \%$ & $4.05[0.39,41.87]$ & & & \\
\hline Stitzenberg 2004 & 3 & 33 & 3 & 108 & $3.5 \%$ & $3.50[0.67,18.24]$ & & & \\
\hline Vaquerano 2006 & 4 & 221 & 2 & 77 & $8.1 \%$ & $0.69[0.12,3.85]$ & & & \\
\hline Wong 2006 & 8 & 150 & 0 & 70 & $1.8 \%$ & $8.41[0.48,147.80]$ & & & \\
\hline Wright 2007 & 22 & 499 & 9 & 121 & $38.3 \%$ & $0.57[0.26,1.28]$ & & & \\
\hline Total $(95 \% \mathrm{Cl})$ & & 1304 & & 1031 & $100.0 \%$ & $1.61[1.06,2.44]$ & & $\nabla$ & \\
\hline Total events & 70 & & 39 & & & & & & \\
\hline $\begin{array}{l}\text { Heterogeneity: } \chi^{2}= \\
\text { Test for overall effect: }\end{array}$ & $\begin{array}{l}6.64, \mathrm{df}= \\
=2.24(\end{array}$ & $\begin{array}{l}11(p= \\
=0.02\end{array}$ & $0.12) ; R$ & $=34 \%$ & & & $\begin{array}{cc}0.001 & 0.1 \\
\text { Favours Clark VI - V }\end{array}$ & $\begin{array}{lc}1 & 10 \\
\text { Favours }\end{array}$ & $\begin{array}{l}1000 \\
\text { lark I - III }\end{array}$ \\
\hline
\end{tabular}

Figure 5. Presence of micrometastases in groups with Clark levels I-III and IV-V

\begin{tabular}{|c|c|c|c|c|c|c|c|c|}
\hline \multirow[b]{2}{*}{ Study or Subgroup } & \multicolumn{2}{|c|}{ Mitoses $\geq 5 / \mathrm{mm}^{2}$} & \multicolumn{2}{|c|}{ Mitoses $<5 / \mathrm{mm}^{2}$} & \multirow[b]{2}{*}{ Weight } & \multirow{2}{*}{$\begin{array}{l}\text { Odds Ratio } \\
\text { M-H, Fixed, } 95 \% \mathrm{Cl}\end{array}$} & \multirow{2}{*}{\multicolumn{2}{|c|}{$\begin{array}{c}\text { Odds Ratio } \\
\text { M-H, Fixed, 95\% Cl }\end{array}$}} \\
\hline & Events & Total & Events & Total & & & & \\
\hline Oliveira Filho 2003 & 3 & 6 & 9 & 178 & $38.6 \%$ & $18.78[3.31,106.46]$ & & \\
\hline Ranieri 2006 & 5 & 23 & 1 & 54 & $61.4 \%$ & $14.72[1.61,134.55]$ & & \\
\hline Total $(95 \% \mathrm{Cl})$ & & 29 & & 232 & $100.0 \%$ & $16.29[3.64,72.84]$ & & \\
\hline Total events & 8 & & 10 & & & & & \\
\hline \multicolumn{7}{|c|}{ Heterogeneity: $\quad \chi^{2}=0.03, d f=1(p=0.85) ; p=0 \%$} & $\begin{array}{ll}0.01 & 0.1 \\
\text { Favours } & \text { mitoses } \geq 5 / \mathrm{mm}^{2}\end{array}$ & $\begin{array}{ccc}4 & 1 & 10 \\
1 & 100\end{array}$ \\
\hline
\end{tabular}

Figure 6. Presence of micrometastases in groups with mitosis rate $\geq 5 / \mathrm{mm} 2$ and mitosis rate $<5 / \mathrm{mm}^{2}$

Recently, non-zero mitotic rate has been investigated as a histological prognostic factor. Three studies analyzed mitosis rate $\geq 1 / \mathrm{mm}^{2(4,9,12)}$. In total, 588 cases were analyzed and 350 cases had mitosis rate $\geq 1 / \mathrm{mm}^{2}$. Of these, 24 had a positive sentinel lymph node. There were 238 cases without mitoses and 5 of these had a positive sentinel lymph node (OR: 2.91; 95\%CI [1.12$\left.7.55] ; I^{2} 68 \%\right)$.

\section{DISCUSSION}

The incidence of cutaneous melanoma is increasing worldwide. Since it has aggressive behavior and is difficult to treat at its more advanced stages, early diagnosis is essential for achieving a cure. Within this context, research on SNB in thin melanoma cases is becoming more and more important. Today, early diagnosis is very often possible through these new studies. Clinical application of the auxiliary diagnostic method of dermoscopy has enabled greater diagnostic accuracy for cutaneous melanoma cases. Moreover, interest in skin lesions within the medical community and among the general public and investments in sun protection and cancer prevention are increasingly leading to earlier diagnosis.

Thin melanomas account for a significant percentage of melanoma cases. Because of this high incidence, prognostic factors for thin melanomas are sought. SNB enables analysis on the behavior of such cases, recurrence and survival rates. Thus, it will be possible to form one group of individuals with highrisk thin melanomas and another group with low-risk thin melanomas.

In the international literature, melanomas are deemed to present high risk when they have the following factors: Breslow thickness $\geq 0.75 \mathrm{~mm}$, presence of ulceration and Clark level > III. The TNM classification group of the American Joint Committee on Cancer (AJCC) for thin melanomas with the presence of ulceration or Clark level IV-V is state T1b. In the absence of these high-risk factors, the state is T1a. Furthermore, some melanoma referral centers have used the factor of Breslow thickness $\geq 0.75 \mathrm{~mm}$ to indicate cases requiring sentinel node biopsy.

This study showed that the presence of positive sentinel nodes correlated with a significantly increased 
frequency of deaths and recurrence. Because of this, positive sentinel nodes may predict poor prognoses for thin melanoma cases. Such patients should undergo lymphadenectomy. On the other hand, negative sentinel nodes led to follow-up with good prognosis.

There is no agreement about the criteria used to choose which patients should undergo sentinel lymph node biopsy. Within this context, it is desirable to know which histological factors are associated with higher risk of micrometastasis. Therefore, the present study also analyzed these factors.

\section{CONCLUSIONS}

The presence of positive sentinel nodes had a statistically significant association with higher numbers of deaths and recurrences.

The histological factors that were significantly associated with the presence of lymph node micrometastases were: Breslow thickness $\geq 0.75 \mathrm{~mm}$, Clark level IV-V, mitoses $\geq 5 / \mathrm{mm}^{2}$ and absence of regression.

Although ulceration did not show any statistically significant association with the presence of positive sentinel nodes, the analysis indicated a tendency towards this.

\section{ACKNOWLEDGMENTS}

Research supported by Fundação de Amparo à Pesquisa do Estado de São Paulo (FAPESP). Scholarship period: February $1^{\text {st }}, 2008$ until October $31^{\text {st }}, 2009$. Research $n^{\circ}$ 2007/57033.

\section{REFERÊNCIAS}

1. Morton DL, Thompson JF, Cochran AJ, Mozzillo N, Elashoff R, Essner R, et al. Sentinel-node biopsy or nodal observation in melanoma. N Engl J Med. 2006;355(13):1307-17.

2. Oliveira Filho RS, Ferreira LM, Biasi LJ, Enokihara MM, Paiva GR, Wagner J. Vertical growth phase and positive sentinel node in thin melanoma. Braz $\mathrm{J}$ Med Biol Res. 2003;36(3):347-50.

3. Reintgen D. Lymphatic mapping and sentinel node harvest for malignant melanoma. J Surg Oncol. 1997;66(4):277-81.

4. Kesmodel SB, Karakousis GC, Botbyl JD, Canter RJ, Lewis RT, Wahl PM, et al. Mitotic rate as a predictor of sentinel lymph node positivity in patients with thin melanomas. Ann Surg Oncol. 2005;12(6):449-58.
5. Nguyen CL, McClay EF, Cole DJ, O'Brien PH, Gillanders WE, Metcalf JS, et al. Melanoma thickness and histology predict sentinel lymph node status. Am J Surg. 2001;181(1):8-11.

6. Guitart J, Lowe L, Piepkorn M, Prieto VG, Rabkin MS, Ronan SG, et al. Histological characteristics of metastasizing thin melanomas: a case-control study of 43 cases. Arch Dermatol. 2002;138(5):603-8.

7. Agnese DM, Abdessalam SF, Burak WE Jr, Magro CM, Pozderac RV, Walker MJ. Cost-effectiveness of sentinel lymph node biopsy in thin melanomas. Surgery. 2003;134(4):542-7; discussion 547-8.

8. Bleicher RJ, Essner R, Foshag LJ, Wanek LA, Morton DL. Role of sentinel lymphadenectomy in thin invasive cutaneous melanomas. J Clin Oncol. 2003;21(7):1326-31.

9. Ranieri JM, Wagner JD, Wenck S, Johnson CS, Coleman JJ 3rd. The prognostic importance of sentinel lymph node biopsy in thin melanoma. Ann Surg Oncol. 2006;13(7):927-32.

10. Thompson JF, Shaw HM. Is sentinel lymph node biopsy appropriate in patients with thin melanomas: too early to tell? Ann Surg Oncol. 2006;13(3):279-81.

11. Vaquerano J, Kraybill WG, Driscoll DL, Cheney R, Kane JM 3rd. American Joint Committee on Cancer clinical stage as a selection criterion for sentinel lymph node biopsy in thin melanoma. Ann Surg Oncol. 2006;13(2):198-204.

12. Wong SL, Morton DL, Thompson JF, Gershenwald JE, Leong SP, Reintgen DS, et al. Melanoma patients with positive sentinel nodes who did not undergo completion lymphadenectomy: a multi-institutional study. Ann Surg Oncol. 2006;13(6):809-16.

13. Lowe JB, Hurst E, Moley JF, Cornelius LA. Sentinel lymph node biopsy in patients with thin melanoma. Arch Dermatol. 2003;139(5):617-21.

14. Bedrosian I, Faries MB, Guerry D 4th, Elenitsas R, Schuchter L, Mick R, et al. Incidence of sentinel node metastasis in patients with thin primary melanoma $(<$ or $=1 \mathrm{~mm})$ with vertical growth phase. Ann Surg Oncol. 2000;7(4):262-7.

15. Jacobs IA, Chang CK, DasGupta TK, Salti GI. Role of sentinel lymph node biopsy in patients with thin $(<1 \mathrm{~mm})$ primary melanoma. Ann Surg Oncol. 2003;10(5):558-61.

16. Puleo CA, Messina JL, Riker Al, Glass LF, Nelson C, Cruse CW, et al. Sentinel node biopsy for thin melanomas: which patients should be considered? Cancer Control. 2005;12(4):230-5.

17. Roulin D, Matter M, Bady P, Liénard D, Gugerli O, Boubaker A, et al. Prognostic value of sentinel node biopsy in 327 prospective melanoma patients from a single institution. Eur J Surg Oncol. 2008;34(6):673-9.

18. Stitzenberg KB, Groben PA, Stern SL, Thomas NE, Hensing TA, Sansbury LB, et al. Indications for lymphatic mapping and sentinel lymphadenectomy in patients with thin melanoma (Breslow thickness $<$ or $=1.0 \mathrm{~mm}$ ). Ann Surg Oncol. 2004;11(10):900-6.

19. Hutin A, Heenen M, Vereecken P, Van Geertruyden J, De Lathouwer O, Steels $E$, et al. Is sentinel lymph node biopsy useful in regressive and/or ulcerated thin cutaneous melanomas? J Eur Acad Dermatol Venereol. 2008;22(4):514-5.

20. Kaur C, Thomas RJ, Desai N, Green MA, Lovell D, Powell BW, et al. The correlation of regression in primary melanoma with sentinel lymph node status. J Clin Pathol. 2008;61 (3):297-300.

21. Morris KT, Busam KJ, Bero S, Patel A, Brady MS. Primary cutaneous melanoma with regression does not require a lower threshold for sentinel lymph node biopsy. Ann Surg Oncol. 2008;15(1):316-22. 